\title{
SELF CLEANING OF EARS BY VARIOUS OBJECTS CAUSES MULTIPLE DISEASES OF EXTERNAL EAR
}

\author{
Syed Muhammad Asad Shabbir Bukhari, Sohail Aslam, Mahrukh Afzal*, Naeem Riaz, Asim Abbas**, Jehangir Ahmed Afridi***, \\ Muhammad Fahad Wasim Khan \\ Pakistan Naval Ship Shifa, Karachi Pakistan, *Fatima Jinnah Medical University Lahore, ${ }^{* *}$ Combined Military Hospital Malir/National University of Medical \\ Sciences (NUMS) Pakistan, ${ }^{* * *}$ Combined Military Hospital Nowshera/National University of Medical Sciences (NUMS) Pakistan
}

\section{ABSTRACT}

Objective: To find out the association of multiple diseases of external ear with the use of various objects and cotton buds.

Study Design: Case control study.

Place and Duration of Study: Ear Nose Throat Department, Pakistan Naval Ship Shifa Karachi, from Jan to Oct 2020.

Methodology: All the patients having multiple diseases of external ear were included as cases. Controls were selected from the healthy volunteers from general populations.

Results: Total number of subjects in this study was 140 with the mean age $25.11 \pm 11.21$ years (2-55 years of age range). Out of them, 82 were male and 58 were female. Odds ratio was 16.07.

Conclusion: There is a solid relationship of illnesses of external ear with the utilization of cotton buds. This detrimental practice should be incapacitated by featuring the notice by brands owners of cotton bud and safety instructions at different instructive levels.

Keywords: Cotton buds, Diseases of ear, Odds ratio, Self-ear cleaning.

How to Cite This Article: Bukhari SMAS, Aslam S, Afzal M, Riaz N, Abbas A, Afridi JA, Khan MFW. SelfCleaning of Ears by Various Objects Causes Multiple Diseases of External Ear. Pak Armed Forces Med J 2021; 71(Suppl-3): S476-478. Doi: https://doi.org/10.51253/pafmj.v1i1.7944

This is an Open Access article distributed under the terms of the Creative Commons Attribution License (https://creativecommons.org/licenses/by-nc/4.0/), which permits unrestricted use, distribution, and reproduction in any medium, provided the original work is properly cited.

\section{INTRODUCTION}

Cleaning is good habit and care of the body is the basic right of a human being. Knowledge regarding the cleaning of ears with various objects like cotton bud, match sticks, fingers and hair pins, should be communicated to masses for quality care of ears. Various objects as mentioned are very injurious to the external ears. These objects include cotton buds which were used for quality care of ears initially but the harmful effects were observed in 1972 in New Zealand. ${ }^{1}$ The medical professionals in general and otolaryngologist in particularly are writing articles and advising patients to stop self-cleaning of ears with any object. Cotton buds are utilized by grown-ups as well as are generally applied in pediatric populace either by kids themselves or by guardians. Ear wounds started by cotton buds are regularly seen in ENT outdoor facilities. ${ }^{2,3}$ Cotton bud and different articles utilization in ear propensity is having solid relationship with neurodermatitis and contact dermatitis of the outer ear. ${ }^{4}$ Cotton bud is additionally connected with intense otitis externa, impaction of wax, burst of tympanic membrane and perichondritis in couple of patients. ${ }^{5-7}$

This study was done to find out the association of multiple diseases of external ear with the use of

Correspondence: Dr Syed Muhammad Asad Shabbir Bukhari, Classified ENT Specialist, PNS Shifa, Rawalpindi Pakistan various objects and cotton buds.

\section{METHODOLOGY}

This case control study was conducted at Ear Nose Throat Department, Pakistan Naval Ship Shifa Karachi, from January to October 2020. Acceptance from Hospital Ethical Committee was acquired on a certificate. Consent from the examination subjects were taken prior to filling the questionnaire for study. Non probability convenience sampling technique was used.

Inclusion Criteria: All the patients having multiple diseases of external ear were included as cases after being examined and diagnosed by the otolaryngologist. Controls were chosen from the sound volunteers from all-inclusive communities for same number of patients in span of study.

Exclusion Criteria: Patients having other diseases of head \& neck region, were debarred from the study.

Odds ratio of the risk (using of various objects and cotton buds to clean the ears) was calculated. Occurrences of the variables were determined by utilizing enlightening measurements of SPSS version 20.

\section{RESULTS}

Number of subjects in this research were 140 with the mean age $25.11 \pm 11.21$ years. Minimum age was 2 years and maximum age was 55 years. Out of 
them, $82(59 \%)$ were male and $58(41 \%)$ were female. The gender distribution by percentage waspresented in Figure. Seventy patients were cases and 70 were the

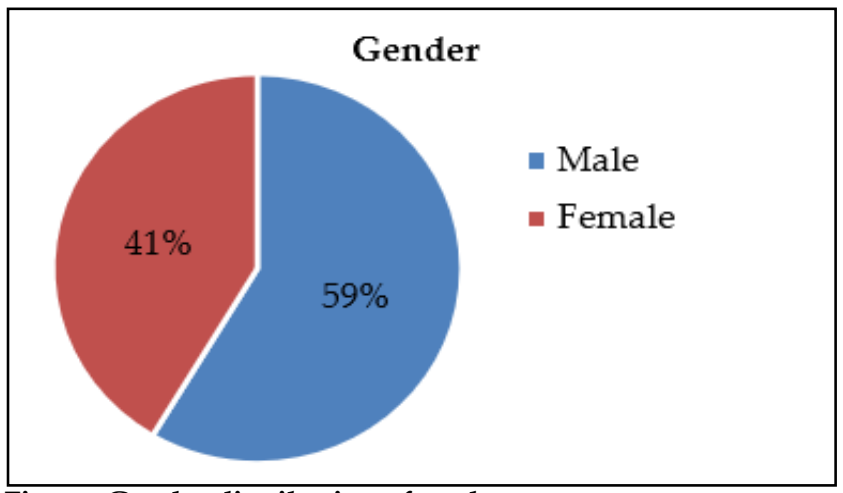

Figure: Gender distribution of study.

controls. Among the cases, 55 were cotton bud/ different article consumers and among the controls it was 13. Odd ratio was 16.07. Table-I is showing the computation and chances proportion. Table-II is showing categories of illnesses of outer ear of the cases $(n=70)$. Out of 70 cases, ${ }^{22}$ were of acute otitis externa, ${ }^{18}$ of wax

Table-I: Risk of use of cotton buds/various objects of external ear.

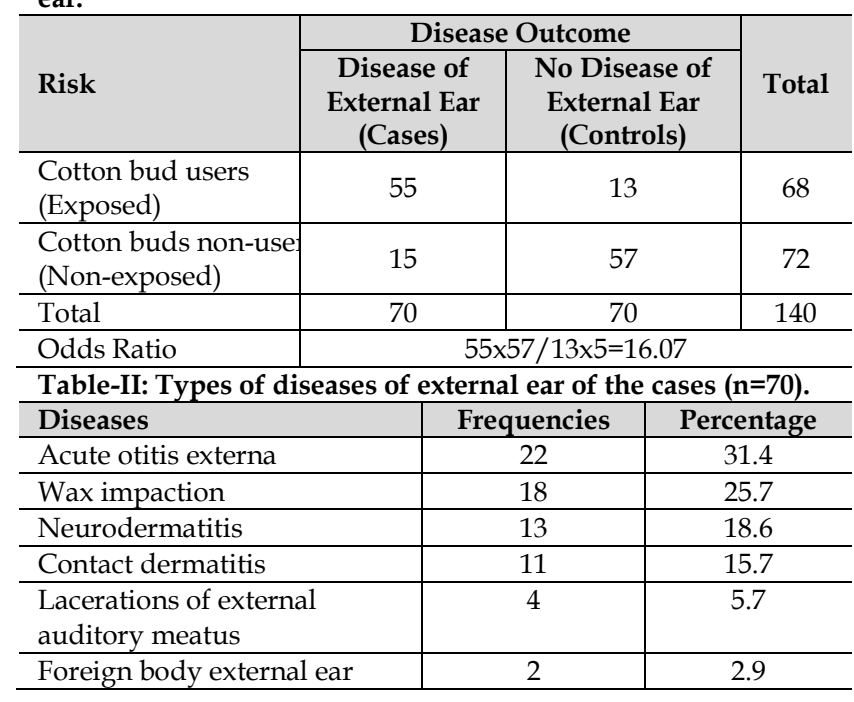

impaction, ${ }^{13}$ of neurodermatitis, ${ }^{11}$ of contact dermatitis, ${ }^{4}$ of lacerations of external auditory meatus and 2 foreign bodies of external ear. Table-III is showing the questionnaire for exposed population of study $(n=68)$. Table-IV is depicting answers to questionnaire by exposed population $(n=68)$. Answers of exposed population used $100 \%$ cotton buds, $76.5 \%$ for more than 1 year and 100\% without knowing the adverse effects. Various objects like fingers, match sticks \& hair pins were also used. Out of $46.5 \%$ of adults used to clean their children's ears with cotton buds.
Table-III: Questionnaire for exposed population of study. Questions

Are you cleaning your ears with some cotton bud?

How long are you using for ears?

Are you having knowledge of adverse effects of cotton bud use?

Are you cleaning your ears with fingers, matchstick, hair pin etc.?

Are you cleaning your children's ear with cotton buds?

Table-IV: Answers to questionnaire by exposed population $(\mathrm{n}=68)$.

\begin{tabular}{l|c|c}
\hline Answers & Numbers & Percentage \\
\hline Yes & 68 & 100 \\
\hline$>1$ year & 52 & 76.5 \\
\hline$<1$ year & 16 & 23.5 \\
\hline No & 68 & 100 \\
\hline Cotton buds & 68 & 100 \\
\hline Fingers & 35 & 51.5 \\
Match sticks & 15 & 22.0 \\
\hline Hair pins & 10 & 14.7 \\
\hline Yes & 31 & 45.6 \\
\hline
\end{tabular}

\section{DISCUSSION}

This study showed that a person with diseases of external ear was 16.07 times more likely to have been exposed to the risk factor (using the cotton buds) than a person without ear disease. The case control concentrate on this subject was completed by Ahmed et al in Darfur, Sudan 4 few years back and odd proportion determined was. ${ }^{12}$ Our study is not only supporting the previous study and showing more association with exposure of cotton buds with ear diseases. All other studies are descriptive and observational studies showing the importance of risk factor and guiding the masses to stop cleaning ears with any object. Gadanya et al, observed thatthere was a high prevalence of cotton bud use for self-e ar cleaning at Aminu Kano Teaching Hospital. This finding had wider implications as doctors 8 were looked upon by the nonprofessional community and other health workers as role models. Khan et al, observed $79.6 \%$ use of cotton buds in undergraduate university students for self-ear cleaning. ${ }^{9}$ Alshehri et al, conducted study in medical and non-medical students, ${ }^{10}$ and the majority (75\%) of the participants practiced self-ear cleaning. These studies are different from our study as we performed on patients and control group. We did not include doctors and medical students in our study. For medical professionals, there was a need to plan and guide out wellbeing instruction and advancement procedures that would spread crucial messages to doctors and other health workers in the local area hospitals, that ear cleaning is vital done via able staffs. Adegbiji et al noticed the commonest object, ${ }^{11}$ utilized in ear cleaning was cotton bud in $44.5 \%$. Different articles were 
digit of hand, plume and key. In our investigation the commonest object was cotton bud, then finger and match stick. Adegbiji et al, additionally led concentrate on children, ${ }^{12}$ and noticed the most well-known justification ear cleaning was because of individual cleanliness. Ear cleaning was done in $57.1 \%$ of the children by their mothers and cotton bud was the most well-known article. In our investigation, $45.6 \%$ of youngsters were cleaned by their guardians by cotton buds.

There is an overall conviction that there isn't anything incorrect with utilizing cotton buds, and this disintegrates the propensity for utilizing cotton buds essentially to reduce manifestations, for example, itching, ${ }^{13}$ expulsion of filth and maybe even with statements of noticed advantages. Tingling ears were the commonest reason, from neurodermatitis and otitis externa of the ear by different investigations.,14 The wax evacuation was the main justification utilizing cotton buds revealed from different studies. ${ }^{15,16}$ Our research did not endorse tingling and wax expulsion as the significant reasons of cotton bud use in our results as in previous studies.

A survey revealed that majority of cotton bud users was uninformed about its harmful influences on ear. ${ }^{17}$ In our investigation, $100 \%$ of uncovered populace was uninformed of the harmful impacts of selfcleaning of ears with cotton buds. Consciousness of cotton-bud related entanglements is a significant general medical problem. Safer strategy for aural toileting and suction may likewise require promoting. ${ }^{18}$

Public mindfulness by all sort of media must be carried out to save people from preventable ear diseases. A few examinations uncovered that neurodermatitis, contact dermatitis, wax impaction, perichondritis and otitis externa 19 are connected with the propensity for self-cleaning of ears with cotton buds. Our investigation results showed these diseases along with lacerations of external auditory meatus and foreign bodies' external ear.

\section{ACKNOWLEDGEMENT}

We are thankful to our parents, teachers and friends.

\section{LIMITATION OF STUDY}

The study is case control on the topic and second in the world. More case control studies and cohort studies should be done to highlight the bad ear cleaning habit.

\section{CONCLUSION}

There is a solid relationship of illnesses of external ear with the utilization of cotton buds on the basis of odd ratio. This detrimental practice should be incapacitated by featuring the notice by brands' owners of cotton bud, safety instruction at different instructive levels and short commu-nity mindfulness talks of otolaryngologists at electronic media and web-based media.

\section{Conflict of Interest: None.}

\section{Authors' Contribution}

SMASB: Conception of work, wrting of introduction, SA: Critical revision, MA: Literature review, NR: Data collection, AA: Data analysis, JAA: Writing of discussion, MFWK: Writing of results.

\section{REFERENCES}

1. Robertson MS. The misuse of cotton wool buds. New Zeal Med J 1972; 75(476): 37-39.

2. Kumar S, Ahmed S. Use of cotton buds and its complications. J Surg Pak (Inter) 2008; 13(3): 137-138.

3. Amutta SB, Yunusa MA, Iseh KR, Obembe A, Egili E, Aliyu1 D et al. Sociodemographic characteristics and prevalence of self ear cleaning in sokoto metropolis. Inter J Otolaryngol Head Neck Surg 2013; 2(1): 276279.

4. Ahmed S, Zaheer SA, Shabbir SM, Rao S, Islam T, Ahmed B. Association of dermatological conditions of external ear with the use of cotton buds. J Enam Med Coll 2014; 4(1): 174-176.

5. Smith M, Darrat I, Seidman M. Otologic complications of Q-tip use: one institution's experience. Laryng 2012; 122(2): 409-411.

6. Kennedy CTC. The external ear. In: Burns T, Breathnach S, Cox N, Griffiths C (eds). Rook's textbook of dermatology. 8th edn. United Kingdom: Wiley Blackwell 2010; 8(1): 27-64.

7. Loock JW. Perichondritis of the external ear. In: Browning GG, Burton MJ, Clarke R, Hibbert J, Jone NS, Lund VJ, Luxon LM, Watkinson JC (eds). Scot-Brown's otorhinolaryngology: head-neck surgery. 7th edn. Great Britain: Hodder Arnold 2008: 2(1): 3358-3361.

8. Gadanya M, Abubakar S, Ahmed A, Maje AZ. Prevalence and attitude of self-ear cleaning with cotton bud among doctors at aminu Kano teaching hospital, Northwestern Nigeria. Niger J Surg Res 2016; 17(2): 43-46.

9. Khan NB, Thaver S, Govender SM. Self-ear cleaning practices and the associated risk of ear injuries and ear-related symptoms in a group of university students. J Public Health Africa 2017; 8(2): 1-5.

10. Alshehri AA, Asiri KA, Saeed M, Alahmari D, Alwabel HH, Alahmari YD, et al. Knowledge, attitudes, and practices of self-ear cleaning among medical and non-medical students at King Khalid University, Abha, Saudi Arabia. Int J Med Dev Ctries 2020; 4(6): 960-967.

11. Adegbiji WA, Olajide TG, Nwawolo CC. Patterns of self ear cleaning among otorhinolaryngology patients in developing country. Asian J Sci Technol 2018; 9(4): 1-5.

12. Adegbiji WA, Olajide TG, Nwawolo CC. Paediatric presentation of ear cleaning in a West African country. Official J College Health Sci Nigeria 2018; 12(3): 1-7.

13. Afolabi AO, Kodiya AM, Bakari A, Ahmad BM. Attitude of self-ear cleaning in black Africans: Any benefit?. East Afr J Public Health 2009; 6(2): 43-45.

14. Nussinovitch M, Rimon A, Volovitz B, Raveh E, Prais D, Amir J. Cottontip applicators as a leading cause of otitis externa. Int J Pediatr Otorhinolaryngol 2004; 68(1): 433-435.

15. Adegbiji WA, Alabi BS, Olajuyin OA, Nwawolo CC. Earwax impaction: symptoms, predisposing factors and perception among Nigerians. J Family Med Prim Care 2014; 3(1): 379-382.

16. Lee LM, Govindaraju R, Hon SK. Cotton bud and ear cleaning - A loose tip cotton bud?. Med J Malay 2005; 60(1): 85-88.

17. Hobson JC, Lavy JA. Use and abuse of cotton buds. J Royal Soc Med 2005; 98(8): 360-361.

18. Nagala S, Singh P, Tostevin P. Extent of cotton-bud use in ears. British J General Pract 2011; 61(592): 662-663.

19. Loock JW. Benign nectrotizing otitis externa. In: Browning GG, Burton MJ, Clarke R, Hibbert J, Jone NS, Lund VJ, Luxon LM. Scot-Brown's otorhinolaryngology: head \& neck surgery. $7^{\text {th }}$ ed. Great Britain: Hodder Arnold, 2008; 2(1): 3332-3335. 